Document downloaded from:

http://hdl.handle.net/10251/50719

This paper must be cited as:

Mitsuuchi Tashima, M.; Akasaki, JL.; Castaldelli, V.; Soriano Martinez, L.; Monzó Balbuena, JM.; Paya Bernabeu, JJ.; Borrachero Rosado, MV. (2012). New geopolymeric binder based on fluid catalytic cracking catalyst residue (FCC). Materials Letters. 80:50-52. doi:10.1016/j.matlet.2012.04.051.

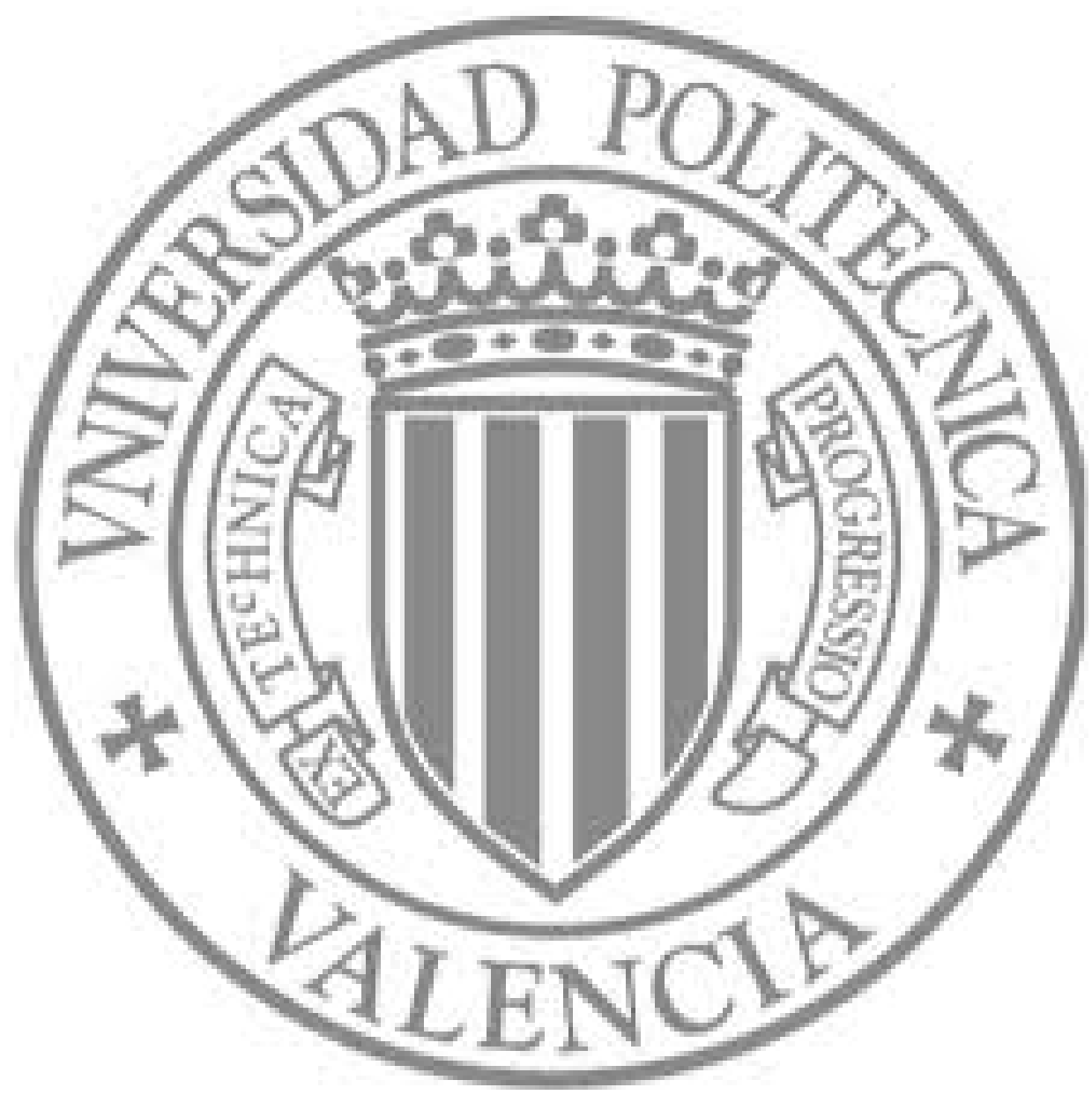

The final publication is available at

http://dx.doi.org/10.1016/j.matlet.2012.04.051

Copyright Elsevier 


\section{New geopolymeric binder based on fluid catalytic cracking catalyst residue (FCC)}

2 M.M. Tashima ${ }^{1}$, J.L. Akasaki ${ }^{2}$, V.N. Castaldelli ${ }^{2}$, L. Soriano ${ }^{1}$, J. Monzó ${ }^{1}$, J. Payá ${ }^{1}$, M.V.

3 Borrachero 1.

4 maumitta@hotmail.com, akasaki@dec.feis.unesp.br,vinicius_castaldelli@hotmail.com,

5 lousomar@upvnet.upv.es, jmmonzo@cst.upv.es, jjpaya@cst.upv.es, vborrachero@cst.upv.es. ${ }^{1}$ Instituto

6 de Ciencia y Tecnología del Hormigón. Universitat Politècnica de València. Camino de Vera s/n, Edificio

7 4G, 46022 Valencia. Spain. ${ }^{2}$ UNESP - Univ Estadual Paulista, Campus de Ilha Solteira. Alameda Bahia,

8 550. CEP:15385-000 Ilha Solteira-SP, Brazil.

$9 \quad *$ Corresponding author: jjpaya @ cst.upv.es, phone +34 963877564.

$10 \quad$ Fax +34963877569

11 Abstract

12 This paper provides information about the synthesis and mechanical properties of geopolymers based on fluid catalytic cracking catalyst residue (FCC). FCC was alkali activated with solutions containing different $\mathrm{SiO}_{2} / \mathrm{Na}_{2} \mathrm{O}$ ratios. The microstructure and mechanical properties were analysed by using several instrumental techniques. FCC geopolymers are mechanically stable, yielding compressive strength about $68 \mathrm{MPa}$ when mortars are cured at $65^{\circ} \mathrm{C}$ during three days. The results confirm the viability of producing geopolymers based on FCC. 


\section{Introduction}

The geopolymerization process is a chemical reaction between an aluminosilicate material and a high alkaline solution, under controlled curing conditions to form NASH gel and some zeolitic structures $[1,2]$.

The first systematic research related to alkali activated materials was carried out in 1957 by Glukhovsky

[3]. After that, a lot of efforts have been made in this area, such us the research done by Palomo et al.

[4,5], Davidovits [6,7] and van Deventer et al. [8-10].

Geopolymers have many advantages over Portland cement, such as similar or higher compressive strength, better fire resistance and more durability [11]. Otherwise, these materials can be considered a low $\mathrm{CO}_{2}$ emission binder due to its reduction up to $80 \%$ in the $\mathrm{CO}_{2}$ emission, when compared to Portland cement [12].

Most of the studies related to alkali activated binders are based on blast furnace slag, fly ashes and metakaolin. However, other aluminosilicate materials can also be used as raw material in the geopolymerization process $[8,13]$. In this paper, the fluid catalytic cracking catalyst residue (FCC) is tested as an aluminosilicate source in the production of geopolymeric binders. This material is a high reactive aluminosilicate one obtained as a byproduct from the petroleum industry. FCC has been successfully used as a supplementary cementitious material (SCM) in Portland cement binders [14]. In general terms, studies about FCC compare its properties with metakaolin (MK) due to their similar chemical composition. Payá et al. [15] concluded that FCC presents higher pozzolanic reactivity at an early age curing than MK, whereas MK has high reactivity for long time curing. Another advantage of using FCC is its low water demand, compared to MK. It allows to produce binders with lower water/binder ratio and, consequently, with higher compressive strength than MK binders. As previously reported $[14,15]$, FCC showed high pozzolanic reactivity when mixed with Portland cement, due to a chemical combination with portlandite $\mathrm{Ca}(\mathrm{OH})_{2}$. In this study we evaluate the role of FCC in a different environment, alkaline too, with the absence of calcium ions, but sodium ions.

Transferring this knowledge to alkali activated systems, it is important to observe that geopolymers based on $\mathrm{MK}$ present high $\mathrm{H}_{2} \mathrm{O} / \mathrm{Na}_{2} \mathrm{O}$ ratio. For these binders, the ultimate compressive strength achieved is in the range of $7.03-13.13 \mathrm{MPa}[16]$.

In this paper, the fluid catalytic cracking catalyst residue (FCC) is tested as an aluminosilicate source in the production of geopolymeric binders. 


\section{Experimental}

2

\subsection{Materials and techniques}

3 of alkaline solution.

\subsection{Dosage and curing conditions}

The spent fluid catalytic cracking catalyst of petroleum (FCC) was used as a raw material in alkali activated binders. FCC is an aluminosilicate material $\left(46.04 \% \mathrm{SiO}_{2}, 47.47 \% \mathrm{Al}_{2} \mathrm{O}_{3}, 0.58 \% \mathrm{Fe}_{2} \mathrm{O}_{3}, 0.11 \%\right.$ $\mathrm{CaO}, 0.17 \% \mathrm{MgO}, 0.30 \% \mathrm{Na}_{2} \mathrm{O}, 0.02 \% \mathrm{~K}_{2} \mathrm{O}$ and some other impurities) with a high pozzolanic reactivity and a mean particle diameter of $17.1 \mu \mathrm{m}$ (after grinding) [14]. Sodium hydroxide (98\% purity) supplied by Panreac S.A. and waterglass $\left(28 \% \mathrm{SiO}_{2} ; 8 \% \mathrm{Na}_{2} \mathrm{O} ; 64 \% \mathrm{H}_{2} \mathrm{O}\right)$ from Merck were used in the preparation

Ultimate mechanical strengths of mortars were obtained by using a universal testing machine, according to UNE-EN-196-1 standard. Flexural strength was obtained as a mean of three values whereas compressive strength was calculated as a mean of six values. Thermogravimetric analyses (TGA) were performed in a TGA 850 Mettler-Toledo thermobalance under nitrogen atmosphere, with pin-holed aluminium sealed crucibles, and a heating rate of $10^{\circ} \mathrm{C} \cdot \mathrm{min}^{-1}$, from $35^{\circ} \mathrm{C}$ until $600^{\circ} \mathrm{C}$. XRD patterns were collected in a Philips diffractometer PW1710 with $\mathrm{Cu}-\mathrm{K} \alpha$ radiation, under routine conditions of $40 \mathrm{Kv}$ and $20 \mathrm{~mA}$, in the $2 \Theta$ range 5-55. Microscopic studies were carried out by means of Scanning Electron Microscopy, by using a JEOL JSM-6300. Water/binder suspensions were monitored at different ages by electrical conductivity and pH measurements: a Crison microCM2201 conductimeter and a Crison micropH2001 pH-meter were used (Alkali-resistant pH-electrode Crison 5204 was used). The analysis was performed using $1 \mathrm{~g}$ of geopolymer paste and a $10 \mathrm{ml}$ of deionized water. A continuous stirring was performed during 10 minutes before the measurement, and then the electrodes were submerged.

Some geopolymeric mortars based on FCC were prepared with an $\mathrm{NaOH}$ solution as alkaline activator to verify the viability of using FCC in geopolymeric binders. All mortars tested presented a water/FCC ratio of 0.60 and a sand/FCC ratio of 3. Compressive strength values of mortars were in the range $1-16 \mathrm{MPa}$ after 7 curing days at $65^{\circ} \mathrm{C}$ in high relative humidity (RH 100\%). Specifically, mortar activated using 5 molal of $\mathrm{NaOH}$ solution yielded 1.20MPa, using 7.5 molal yielded 3.40MPa and 10 molal yielded 15.17MPa. The best result was observed for the highest $\mathrm{NaOH}$ concentration. Mortar activated using 10 molal $\mathrm{NaOH}$ was also tested after 3 curing days in the same conditions: the compressive strength was 16.46MPa. This behaviour suggests that the activation using only $\mathrm{NaOH}$ did not improve mechanical 
1 properties due to the lack of silicate anions in the activating solution. Additionally, an increase in the curing time did not produce better mechanical behaviour.

Thus, a new set of alkaline solutions based on mixture of sodium silicate and sodium hydroxide solution were tested in order to increase their mechanical properties. The total $\mathrm{Na}^{+}$concentration was fixed in 10 molal, varying the amount of dissolved $\mathrm{SiO}_{2}$. The alkaline solution compositions are listed in Table 1 . For this set of mortars, samples were cured for 3 days at $65^{\circ} \mathrm{C}$ in high relative humidity (RH 100\%). As it can be observed, the $\mathrm{SiO}_{2} / \mathrm{Na}_{2} \mathrm{O}$ molar ratio was in the range 0-1.46.

Table 1. Alkaline activating solutions of geopolymers based on FCC.

\section{Results and Discussion}

Mechanical strength values of geopolymers with different $\mathrm{SiO}_{2} / \mathrm{Na}_{2} \mathrm{O}$ ratio are shown in Figure 1. For alkaline solutions with $\mathrm{SiO}_{2} / \mathrm{Na}_{2} \mathrm{O}$ ratio lower than 0.4 , both mechanical strengths, compressive and flexural, are significantly low. However, for higher $\mathrm{SiO}_{2} / \mathrm{Na}_{2} \mathrm{O}$ ratios, an improvement in mechanical properties is observed. This behaviour suggests the importance of dissolved $\mathrm{SiO}_{2}$ in these systems. Thus, flexural strength higher than $10 \mathrm{MPa}$ was obtained for $\mathrm{SiO}_{2} / \mathrm{Na}_{2} \mathrm{O}$ ratio in the $0.8-1.5$ range. Concerning compressive strength, the maximum value $(68.34 \mathrm{MPa})$ was obtained for $\mathrm{SiO}_{2} / \mathrm{Na}_{2} \mathrm{O}$ ratio of 1.19 . The results suggest that the activation of this aluminosilicate requires the use of a mixture of waterglass $/ \mathrm{NaOH}$.

Figure 1. Mechanical strength for geopolymers based on $\mathrm{FCC}$ using different $\mathrm{SiO}_{2} / \mathrm{Na}_{2} \mathrm{O}$ ratio.

The nature of the geopolymeric gel generated by reaction of FCC and alkaline solution was tested by means of TG, SEM and XRD studies. Thermogravimetric analysis of FCC pastes which use activating solutions with different $\mathrm{SiO}_{2} / \mathrm{Na}_{2} \mathrm{O}$ ratios were carried out for 1-day and 3-days curing times at $65^{\circ} \mathrm{C}$. A continuous loss of weight was observed from $100^{\circ} \mathrm{C}$, finding a peak centered at $140-160^{\circ} \mathrm{C}$ in the DTG curve, typical of geopolymeric gels [17].This loss of weight is associated to the volatilization of water molecules and/or $\mathrm{OH}^{-}$groups from the products formed in the geopolymerization process. The increase in the loss of weight with curing time (e.g., from $13.3 \%$ to $15.13 \%$ for AA-FCC0.88 paste) is attributed to the progress of geopolymeric gel formation. 
2 The geopolymerization reaction was also monitored by means of the electrical conductivity and $\mathrm{pH}$

3 values of the paste with $\mathrm{SiO}_{2} / \mathrm{Na}_{2} \mathrm{O}$ ratio of 1.9 (see experimental section). The $\mathrm{pH}$ of the paste diminished strongly in the first 2 hours, from 13.01 to 12.49 . This fact is related to the dissolution of the $\mathrm{Al}_{2} \mathrm{O}_{3} / \mathrm{SiO}_{2}$ framework of the FCC. From 2 hours to 7 days, the $\mathrm{pH}$ decreases from 12.49 to 12.42. These results suggest that the alkaline media attacks the mineral addition easily. In the same way, the electrical conductivity of paste suspensions was measured: thus, an important decrease from 23.1 to $12.77 \mathrm{microS} / \mathrm{cm}$ was observed for the first 2 hours of reaction. The decrease in electrical conductivity was from 12.77 to $7.3 \mathrm{microS} / \mathrm{cm}$ for the period 2 hours-7days; this means that the measurements in electrical conductivity showed higher sensitivity than $\mathrm{pH}$ measurements. The decrease in electrical conductivity was related to the chemical combination of $\mathrm{Na}^{+}, \mathrm{OH}^{-}$groups and silicate anions in the geopolymeric matrix.

XRD patterns were measured (see figure 2) for $\mathrm{FCC}$ and for two activated pastes: 0 and $1.17 \mathrm{SiO}_{2} / \mathrm{Na}_{2} \mathrm{O}$ ratio (after 3 days of curing at $65^{\circ} \mathrm{C}$ ). FCC was an aluminosilicate-based mineral addition with some crystallized compounds: acid-faujasite (in sodium form $\mathrm{Na}_{2} \mathrm{Al}_{2} \mathrm{Si}_{4} \mathrm{O}_{12} .8 \mathrm{H}_{2} \mathrm{O}$, PDFcard-391380) is identified as the main mineral compound. A baseline deviation was observed in the $17-32^{\circ} 2 \Theta$ range, means that the amorphous fraction in the FCC was transformed after the chemical activation process.

Figure 2. XRD patterns for FCC and geopolymers based on FCC. detailed view of microstructure of AA-FCC0. A porous matrix and the presence of partially reacted FCC are observed. Nevertheless, AA-FCC0.88 paste (Figure 3b) has a dense-compact microstructure 
Figure 3. SEM micrographs of alkali activated FCC pastes cured at $65^{\circ} \mathrm{C}$ during 3 days: a) AA-FCC 0; b) AA-FCC 0.88.

\section{Conclusions}

$6 \quad$ FCC is an inorganic industrial waste that can be used for preparing geopolymers. Activation of FCC by

$7 \mathrm{NaOH} /$ waterglass mixture at $65^{\circ} \mathrm{C}$ let us produce a stable binder and mortars with compressive strength in the range of $8.52-68.34 \mathrm{MPa}$.

9 Microstructural studies have revealed that increasing the $\mathrm{SiO}_{2} / \mathrm{Na}_{2} \mathrm{O}$ ratio, an amorphous, dense-compact microstructure can be obtained.

\section{Acknowledgments}

To the Ministerio de Ciencia e Innovación (MICINN) of the Spanish Government (MAT-2011-19934 project). To the PROPG - UNESP “Universidade Estadual Paulista Julio de Mesquita Filho”, Brasil.

\section{References}

[1] A. Fernández-Jiménez, A. Palomo, Cem Concr Res 2005; 35; 1984-1992.

[2] J.R. Gasca-Tirado, J.C. Rubio-Ávalos, M.S. Muñiz-Villarreal, A. Manzano-Ramírez, J.L. ReyesAraiza, S. Sampieri-Bulbarela, C. Villaseñor-Mora, J.J. Pérez-Bueno, L.M. Apatiga, V. Amigó Borrás, Mater Lett $2011 ; 65 ; 880-883$.

[3] C. Shi, A.F. Jiménez, A. Palomo, Cem Concr Res 2011; 41; 750-763.

[4] A. Palomo, M.W. Grutzeck, M.T. Blanco, Cem Concr Res 1999; 29; 1323-1329.

[5] A. Fernandez-Jimenez, I. García-Lodeiro, A. Palomo, J Mater Sci 2007; 42; 3055-3065.

[6] J. Davidovits, J Therm Anal Calorim 1991; 37; 1633-1656.

[7] J. Davidovits, J Mater Edu 1994; 91-139.

[8] H. Xu, J.S.J. Van Deventer, Int J Min Process 2000; 59; 247-266.

[9] W.K.W. Lee, J.S.J. van Deventer, Colloids Surf Physicochemical Eng Aspects 2002; 211; 49-66.

[10] J. van Deventer, J. Provis, P. Duxson, D. Brice, Waste Bio Val 2010; 1; 145-155.

[11] J. Davidovits, Geopolymer chemistry and aplications., 2nd ed., France, 2008.

[12] E. Gartner, Cem Concr Res 2004; 34; 1489-1498. 
1 [13] F. Pacheco-Torgal, J. Castro-Gomes, S. Jalali, Const Build Mater 2008; 22; 1201-1211.

2 [14] J. Payá, J. Monzó, M.V. Borrachero, Cem Concr Res 1999; 29; 1773-1779.

3 [15] J. Payá, J. Monzó, M.V. Borrachero, S. Velázquez, Cem Concr Res 2003, 33; 603-609.

4 [16] M.S. Muñiz-Villarreal, J.L. Reyes-Araiza, S. Sampieri-Bulbarela, J.R. Gasca-Tirado, A. Manzano-

5 Ramírez, J.C. Rubio-Ávalos, J.J. Pérez-Bueno, L.M. Apatiga, A. Zaldivar-Cadena, V. Amigó-Borrás,

$6 \quad$ Mater Lett $2011 ; 65 ; 995-998$.

7 [17] S.A. Bernal, R.M. de Gutierrez, J.L. Provis, V. Rose, Cem Concr Res 2010; 40; 898-907.

8

9

10

11

12

13

14

15

16

17

18

19

20

21

22 
2 Figure 1. Mechanical strength for geopolymers based on FCC using different $\mathrm{SiO}_{2} / \mathrm{Na}_{2} \mathrm{O}$ ratio.

3

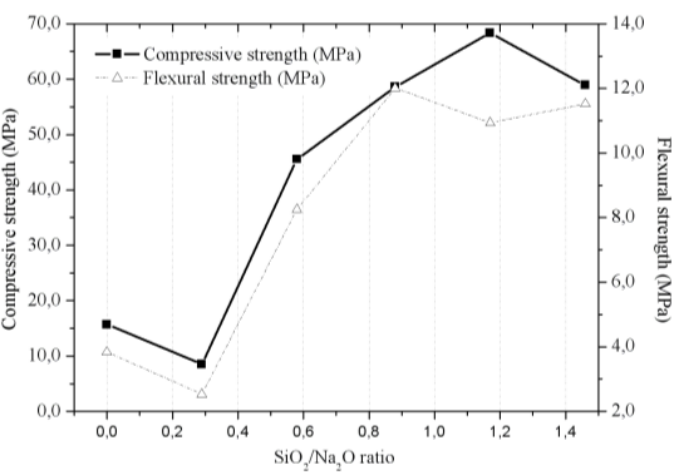

Figure 2. XRD patterns for FCC and geopolymers based on FCC.

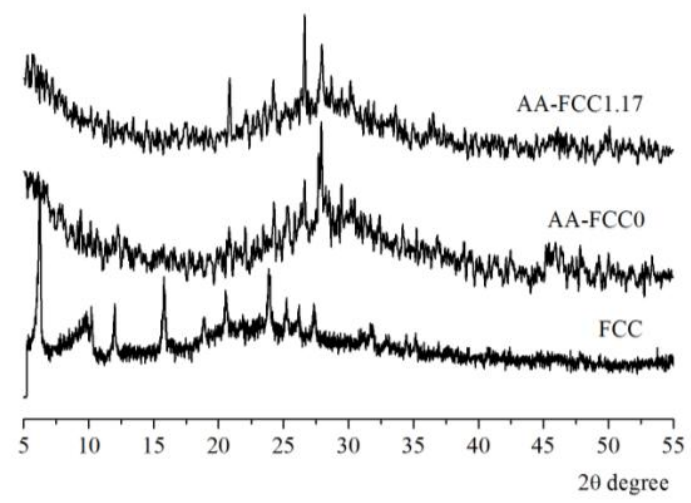

6

Figure 3. SEM micrographs of alkali activated FCC pastes cured at $65^{\circ} \mathrm{C}$ during 3 days: a) AA-FCC 0 ; b)

AA-FCC 0.88.

8

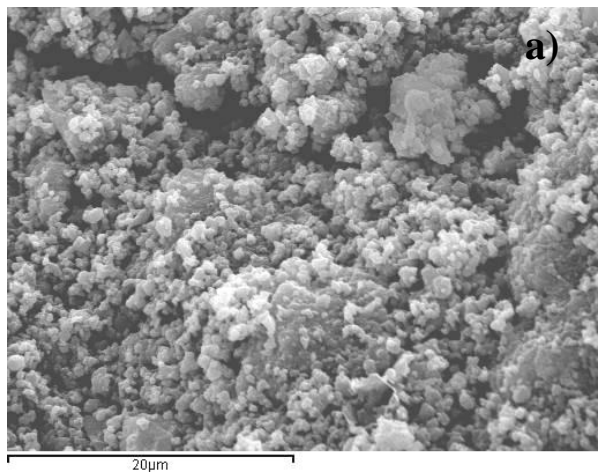

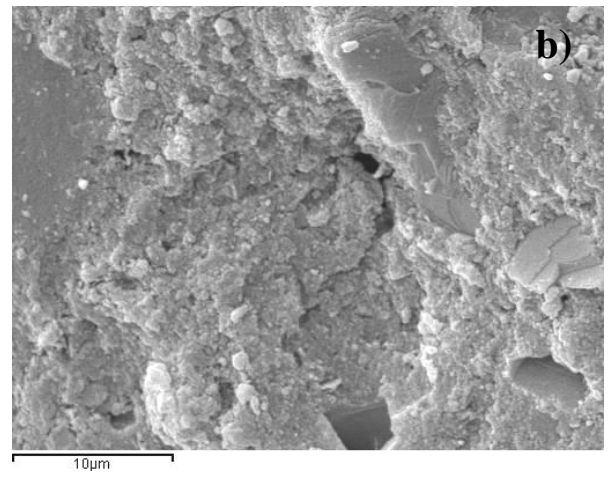

9

10 Table 1. Alkaline activating solutions of geopolymers based on FCC.

\begin{tabular}{ccccc}
\hline & $\mathrm{Na}_{2} \mathrm{O}(\mathrm{mol})$ & $\mathrm{SiO}_{2}(\mathrm{~mol})$ & $\mathrm{H}_{2} \mathrm{O} / \mathrm{Na}_{2} \mathrm{O}$ & $\mathrm{SiO}_{2} / \mathrm{Na}_{2} \mathrm{O}$ \\
\hline AA-FCC 0 & 1.35 & 0 & 11.11 & 0 \\
AA-FCC 0.29 & 1.35 & 0.39 & 11.11 & 0.29 \\
AA-FCC 0.58 & 1.35 & 0.79 & 11.11 & 0.58 \\
AA-FCC 0.88 & 1.35 & 1.18 & 11.11 & 0.88 \\
AA-FCC 1.17 & 1.35 & 1.58 & 11.11 & 1.17 \\
AA-FCC 1.46 & 1.35 & 1.97 & 11.11 & 1.46 \\
\hline
\end{tabular}


